\title{
Mechanochemical reduction of manganese dioxide by grinding in organic vapors
}

\author{
Osami $\mathrm{ABE}^{\dagger}$ and Takahiro SANO
}

The Research Center for Superplasticity, Ibaraki University, 4-12-1 Nakanarusawa, Hitachi, Ibaraki 316-8511

\begin{abstract}
Mechanochemical redox reactions of manganese dioxide with organic vapors have been studied to control the chemical valence (oxidation number) of manganese ions under grinding. Electrolytic-manganese dioxide (EMD) including double chains of edgesharing $\mathrm{MnO}_{6}$-octahedra transforms into $\beta$ - $\mathrm{MnO}_{2}$ (Pyrolusite) consisting of the single chains under grinding in Ar. The mechanical dissociation of the double chains generates active sites to adsorb the atmospheric $\left(\mathrm{CH}_{3}\right)_{2} \mathrm{CO}$ vapor and the strongly adsorbed $\left(\mathrm{CH}_{3}\right)_{2} \mathrm{CO}$ molecules pull out the oxide ions from $\mathrm{MnO}_{2}$ to reduce $\mathrm{Mn}^{4+}$ to $\mathrm{Mn}^{3+}$ ions, while $\left(\mathrm{CH}_{3}\right)_{2} \mathrm{CO}$ is oxidized to $\mathrm{CO}_{2}$ and $\mathrm{H}_{2} \mathrm{O}$ via the intermediate oxidation products, $\mathrm{HCOH}$ and $\mathrm{CH}_{3} \mathrm{COH}$. One $\left(\mathrm{CH}_{3}\right)_{2} \mathrm{CO}$ molecule can reduce $16 \mathrm{MnO}_{2}$ units to trivalent $\mathrm{MnO}_{1.5}$ (Bixbyite). However, the decomposition products, $\mathrm{CO}_{2}$ and $\mathrm{H}_{2} \mathrm{O}$, occupying the adsorption sites dominantly to $\left(\mathrm{CH}_{3}\right)_{2} \mathrm{CO}$ disturb the redox process. This mechanochemical reduction of $\mathrm{MnO}_{2}$ can be applied to the synthesis of $\mathrm{LiMn}^{\mathrm{III}} \mathrm{Mn}^{\mathrm{IV}} \mathrm{O}_{4}$ powder from both combinations of the starting mixtures of $\mathrm{MnO}_{2}-\mathrm{LiOH}$ and $\mathrm{MnO}_{2}-\mathrm{Li}_{2} \mathrm{CO}_{3}$. Some alcohols and ketones also provide the similar reduction ability.
\end{abstract}

(C2009 The Ceramic Society of Japan. All rights reserved.

Key-words : Mechanochemistry, Grinding, Reduction, Valence, Manganese oxide, Organic vapors, Lithium manganate

[Received May 14, 2009; Accepted August 20, 2009]

\section{Introduction}

Mechanochemical process based on the enhanced chemical reactivity of finely ground and activated particles under grinding is expected as one of the candidate synthesis routes of inorganic powders. ${ }^{1)-3)}$ This process can be successfully applied to the synthesis of titanates, ${ }^{4)-6)}$ ferrites, ${ }^{7)-11)}$ manganates, ${ }^{12)}$ cobaltates, ${ }^{13)}$ and others. In these applications, the chemical valence (oxidation number) of the available starting materials is sometimes different from that of the desired products. For example, there are few trivalent nickel and cobalt compounds available for the synthesis of $\mathrm{LiNi}^{\mathrm{III}} \mathrm{O}_{2}$ and $\mathrm{LaCo}^{\mathrm{III}} \mathrm{O}_{3}$. For the synthesis of $\mathrm{LiMn}^{\mathrm{III}} \mathrm{Mn}^{\mathrm{IV}} \mathrm{O}_{4}$, either the partial oxidation of the starting $\mathrm{Mn}_{2} \mathrm{O}_{3}$ or the partial reduction of the starting $\mathrm{MnO}_{2}$ is required. Then, if we can control the redox reactions under grinding, the applicability of mechanochemical processes becomes wide.

For the redox processes, there are many available oxidizing reagents such as $\mathrm{H}_{2} \mathrm{O}_{2}, \mathrm{HClO}_{4}$ and $\mathrm{HNO}_{3},{ }^{8-10)}$ but there are a few reducing reagents. Then, the possibility of some organic compounds as the reducing reagent to $\mathrm{MnO}_{2}$ under grinding has been studied. Under the grinding processes, newly developed solid surface strongly adsorbs environmental gases, vapors and liquids (chemisorption). ${ }^{1)}$ If the chemisorbed vapors can pull-out oxide ions, the solid materials are reduced. However, few papers describe the reactions of solids with gases under grinding. In the present paper, the effect of Acetone (boiling point, $b p=56.3^{\circ} \mathrm{C}$ ), 2-Butanone $\left(b p=79.5^{\circ} \mathrm{C}\right)$, 3-Propanone $\left(b p=101.7^{\circ} \mathrm{C}\right)$, Methanol $\left(b p=64.7^{\circ} \mathrm{C}\right)$ and Ethanol $\left(b p=78.3^{\circ} \mathrm{C}\right)$ on the reduction of $\mathrm{MnO}_{2}$ have initially been examined. Then, the process is applied to the synthesis of $\mathrm{LiMn}_{2} \mathrm{O}_{4}$ as the cathode material for lithium batteries.

Corresponding author: O. Abe; E-mail: abe @mx.ibaraki.ac.jp

\section{Experimental}

A reagent-grade $\mathrm{MnO}_{2}$ powder (electrolytic- $\mathrm{MnO}_{2}, \mathrm{EMD}$ with the structural similarity to $\gamma-\mathrm{MnO}_{2}$, Wako Pure Chemical, Industries, Ltd.) was used after drying for more than $24 \mathrm{~h}$ in an air convection oven. The specific surface area (SSA) of the EMD was $30.3 \mathrm{~m}^{2} \cdot \mathrm{g}^{-1}$. The EMD $(10 \mathrm{~g})$ was encapsulated into the grinding vessel (stainless steel, capacity: $420 \mathrm{~cm}^{3}$ ) with grinding media ( $\phi 2 \mathrm{~mm}$ - YTZ balls). The fractional filling of the grinding media was fixed at 0.40 . The air in the vessel was evacuated and the vapor of the organic compounds was charged from a vaporizer $\left(80-100^{\circ} \mathrm{C}\right)$ attached to the gas line kept at $100^{\circ} \mathrm{C}$ by the use of an Ar gas as the carrier. The amount of distilled Acetone charged was $0 \mathrm{~cm}^{3}$ (A0, Ar atmosphere), $0.1 \mathrm{~cm}^{3}$ (A1), $0.2 \mathrm{~cm}^{3}$ (A2), $0.3 \mathrm{~cm}^{3}$ (A3), $0.4 \mathrm{~cm}^{3}$ (A4), $0.5 \mathrm{~cm}^{3}$ (A5) and $1.0 \mathrm{~cm}^{3}$ (A10). The EMD powder was planetary-milled (KurimotoTekko-Sho) in these atmospheres at the revolution frequency $\left(f_{\text {rev }}\right)$ of $6.0 \mathrm{~s}^{-1}$ for $3 \mathrm{~h}$ with the cooling intervals for $15 \mathrm{~min}$ in every $1 \mathrm{~h}$-grinding, where the temperature inside the vessel was kept at $45-50^{\circ} \mathrm{C}$. On the assumption of the complete vaporization, partial pressure of Acetone inside the vessel is $11.5 \mathrm{kPa}$ (A1) $-115 \mathrm{kPa}(\mathrm{A} 10)$ at $50^{\circ} \mathrm{C}$, while the saturated vapor pressure calculated by Antoine's equation is $81.3 \mathrm{kPa}$ corresponding to $0.71 \mathrm{~cm}^{3}$ of the charged Acetone. Then, $0.29 \mathrm{~cm}^{3}$ Acetone is condensed as liquid at the initial grinding stage of A10. The reduction ability of 2-Butanone (B3), 3-Pentanone (P3), Methanol (M3), and Ethanol (E3) was also examined by the same procedure $\left(0.3 \mathrm{~cm}^{3}\right)$.

For the synthesis of $\mathrm{LiMn}_{2} \mathrm{O}_{4}$, stoichiometric mixtures of EMD and the reagent-grade $\mathrm{LiOH}$ or $\mathrm{Li}_{2} \mathrm{CO}_{3}(15.0 \mathrm{~g}$ as $\mathrm{LiMn}_{2} \mathrm{O}_{4}$ ) were encapsulated into the vessel with the grinding media and the atmosphere was substituted to Ar containing $0.5 \mathrm{~cm}^{3}$-Acetone. After the mill-treatment at $6 \mathrm{~s}^{-1}$ for $3 \mathrm{~h}$, the ground products were sieved (60 mesh) in a grove bag filled with a dry Ar gas and then heat-treated isothermally between 300 and 
$900^{\circ} \mathrm{C}$ in air.

The ground powders were identified by X-ray diffractometry (XRD) with $\mathrm{Cu} \mathrm{K} \alpha$ radiation and X-ray photoelectron spectrometry (XPS) with $\mathrm{MgK} \alpha$ radiation. The specific surface area (SSA) was determined by a $\mathrm{N}_{2-}$ adsorption BET method. Thermal analyses (TG DTA) was performed at the heating rate of 10 $\mathrm{K} \cdot \mathrm{min}^{-1}$ in a flowing air. The morphology was observed by SEM. The gaseous decomposition products were identified by GCmass, where a small portion of the ground product was sealed into the glass-capsule quickly in the grove bag and the gases were released by heating in the equipment.

\section{Results and discussion}

\subsection{Solid and gaseous products under grinding in Acetone-containing atmosphere}

Figure 1 shows the XRD profiles of the ground $\mathrm{MnO}_{2}$. The $\gamma$ $\mathrm{MnO}_{2}$-like structure of EMD transformed to $\beta-\mathrm{MnO}_{2}$ (Pyrolusite) in $\mathrm{Ar}$ without containing Acetone (A0). The small amounts of Acetone (A1 and A2) did not reduce $\mathrm{MnO}_{2}$, but the amorphization of $\beta-\mathrm{MnO}_{2}$ progressed. The reduction of $\mathrm{MnO}_{2}$ to $\mathrm{Mn}_{2} \mathrm{O}_{3}$ (Bixbyite) was observed when the Acetone content exceeded $0.3 \mathrm{~cm}^{3}$ (A3). The crystallinity of $\mathrm{Mn}_{2} \mathrm{O}_{3}$ improved with an increase in the Acetone content. The transformation of $\gamma-\mathrm{MnO}_{2}$ to $\beta-\mathrm{MnO}_{2}$ indicates the dissociation of the double chains of edge-sharing $\mathrm{MnO}_{6}$-octahedra of EMD and the rearrangement to the single chains as indicated in Fig. 2. It is considered that the reduction was caused by Acetone molecules adsorbed on the breakage of the double chains. If the oxide ions at the corner of the octahedra are removed by Acetone, the $\mathrm{MnO}_{6}$-octahedra can be rearranged to the structure of $\mathrm{Mn}_{2} \mathrm{O}_{3}$. Under the thermal processes, the transformation occurs at 200$400^{\circ} \mathrm{C}$ and the reduction progresses at $561{ }^{\circ} \mathrm{C}$ with the mass loss of $9.2 \%{ }^{11)}$ Contrary, the ambient temperature inside the vessel was $45-50^{\circ} \mathrm{C}$ and the increase in temperature was mostly due to the heat of friction of the bearing supporting the vessel. Then, the mechanically induced breakage of the double chains is strongly suggested, although the heat of friction of the grinding media and

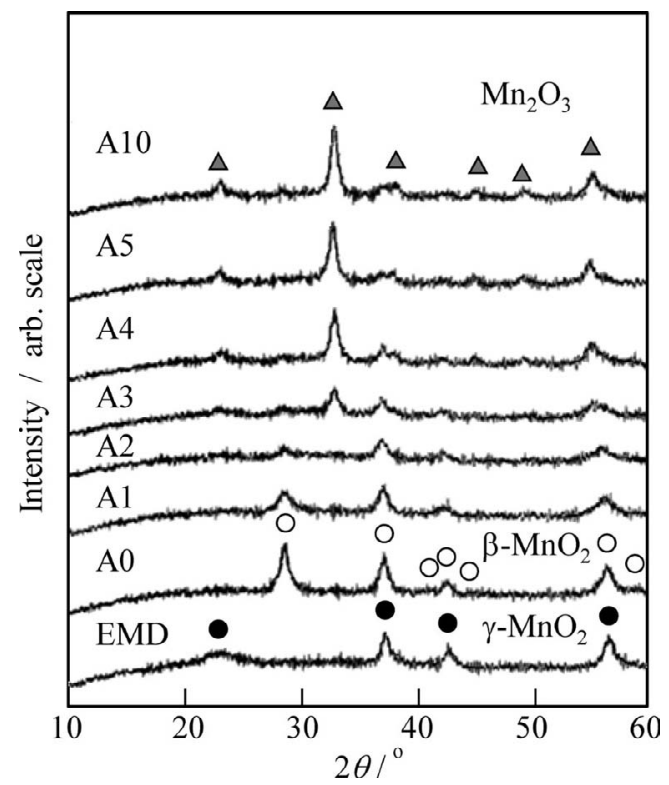

Fig. 1. X-ray diffraction (XRD) profiles of the ground products in a pure $\operatorname{Ar}$ gas (A0) and in the atmosphere containing 0.1(A1), 0.2 (A2), 0.3 (A3), 0.4 (A4), 0.5 (A5), or $1.0 \mathrm{~cm}^{3}$ (A10) Acetone. the mechanical-thermal activation are the alternative mechanisms to be considered.

The Mn3p XPS spectra are shown in Fig. 3. The Mn3p spectra indicated the increase in $\mathrm{Mn}^{\mathrm{III}}$ peak at $47.7 \mathrm{eV}$ with the increase in Acetone content in compensation to the decrease in $\mathrm{Mn}^{\mathrm{IV}}$ peak at $48.5 \mathrm{eV}$. The other peak at $51.0 \mathrm{eV}$ indicated the adsorbed $\mathrm{H}_{2} \mathrm{O}$ on the surface. The valence of surface manganese ions for A5 was determined as 3.37 by referring the peak intensities of standard $\mathrm{MnO}_{2}$ and $\mathrm{Mn}_{2} \mathrm{O}_{3}$ powders. The thermogravimetric curves of the ground products illustrated in Fig. $\mathbf{4}$ also showed the reduction of $\mathrm{MnO}_{2}$ under grinding. The mass loss at $560^{\circ} \mathrm{C}$ for the reduction of $\mathrm{MnO}_{2}$ to $\mathrm{Mn}_{2} \mathrm{O}_{3}$ decreased from $9.20 \%$ for the stoichiometric reaction, $\mathrm{MnO}_{2} \rightarrow \mathrm{MnO}_{1.5}+1 / 2 \mathrm{O}_{2}$, to $8.03 \%$ for $\mathrm{A} 0$ and $3.51 \%$ for A5. The surface valence obtained from the XPS and the bulk valences calculated from the mass loss are plotted against the molar ratio of Acetone to $\mathrm{MnO}_{2}$ in Fig. 5 . Both values decreased with the increase in the Acetone content and terminated at 3.36 for A5 and A10. The trivalent $\mathrm{Mn}_{2} \mathrm{O}_{3}$ phase appeared when the average valence was reduced to 3.6 (A3).

The gas chromatogram and the mass spectra of the gaseous

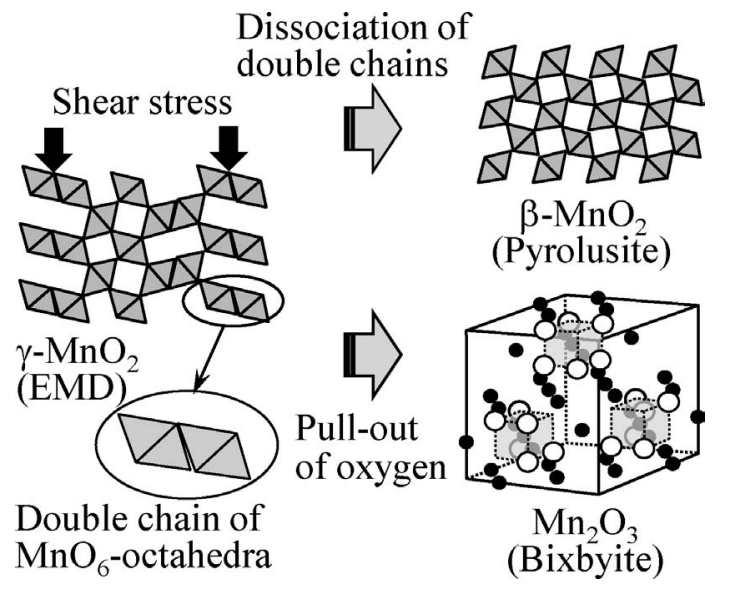

Fig. 2. Phase transformation and reduction of $\mathrm{MnO}_{2}$ under grinding.

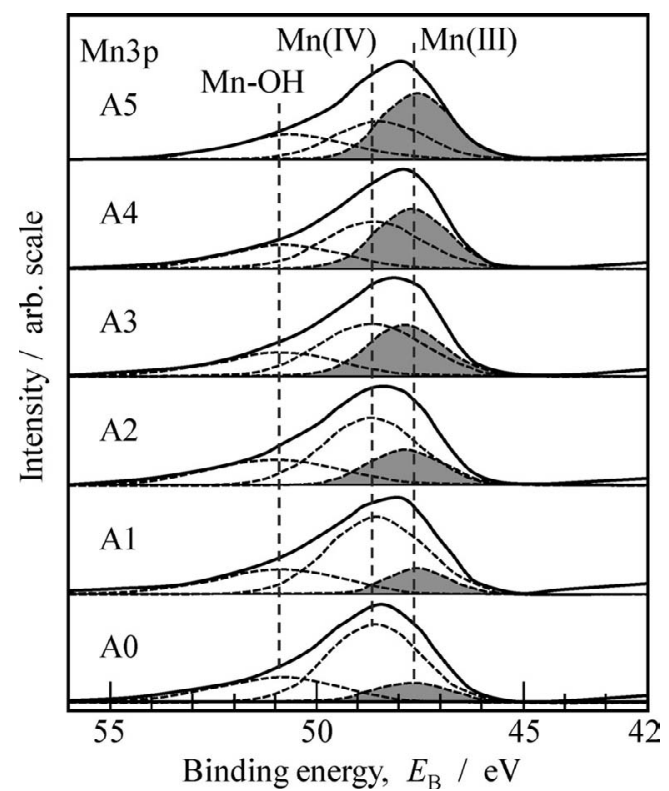

Fig. 3. X-ray photoelectron spectra $(\mathrm{Mn} 3 \mathrm{p})$ of the ground products. 


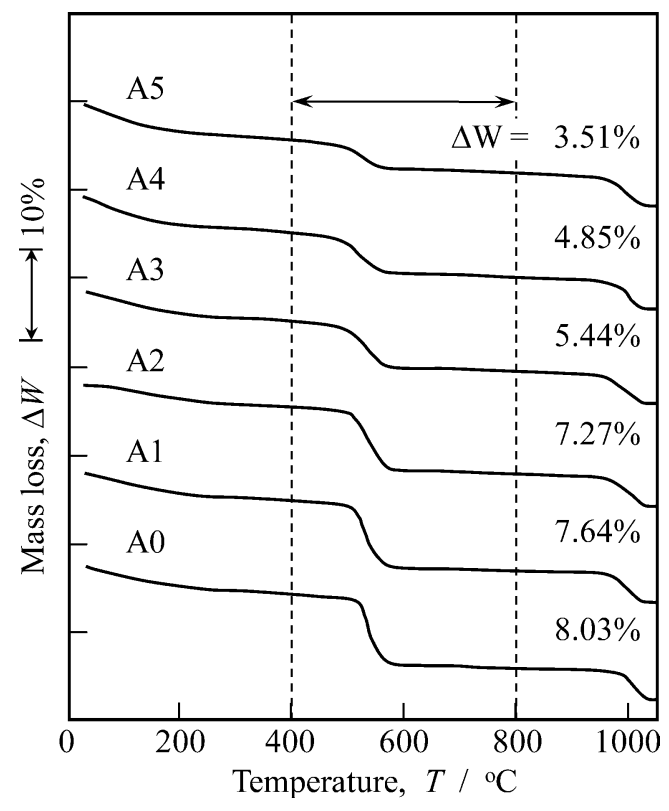

Fig. 4. Thermogravimetric (TG) curves of the ground products. Heating rate: $10 \mathrm{~K} \cdot \mathrm{min}^{-1}$, Atmosphere: flowing air $\left(100 \mathrm{~cm}^{3} \cdot \mathrm{min}^{-1}\right)$.

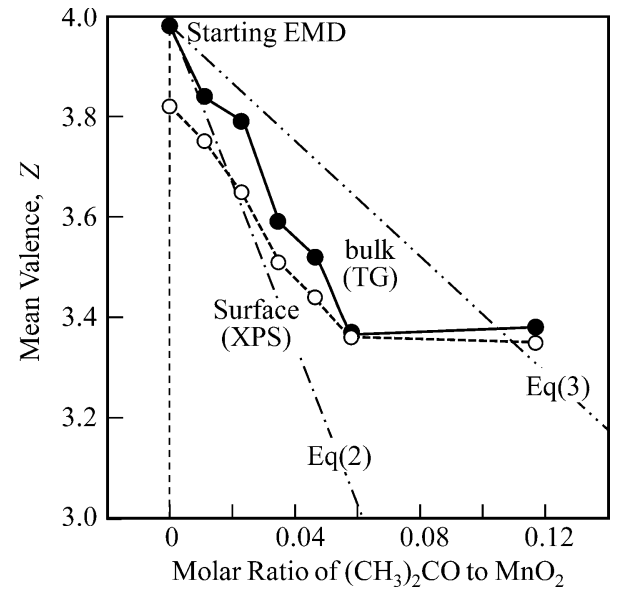

Fig. 5. Chemical valence of surface and bulk manganese ions in the ground products determined by XPS and TG, respectively.

products for A5 are shown in Fig. 6. The gaseous products indicating the short retention time had the two mass numbers of 40 and 44. One of them having the mass number of 40 was $\mathrm{Ar}$ occluded in the ground products. There are two possibilities for the other gas with the mass number of $44, \mathrm{CH}_{3} \mathrm{COH}$ and $\mathrm{CO}_{2}$.

\subsection{Discussion on reduction mechanism}

The initial process of the reduction is supposed to be the pullout of $\mathrm{O}^{2-}$ ions by the strongly adsorbed Acetone molecules on the breakage sites of the double chains, where the Acetone molecule disproportionated into $\mathrm{CH}_{3} \mathrm{CHO}$ and $\mathrm{HCHO}$ according to the following reaction (1). The Gibbs free energy change $(\Delta G)$ for the reaction (1) is $-38.7 \mathrm{~kJ} \cdot \mathrm{mol}^{-1}$.

$$
\left(\mathrm{CH}_{3}\right)_{2} \mathrm{CO}+2 \mathrm{MnO}_{2} \rightarrow \mathrm{CH}_{3} \mathrm{CHO}+\mathrm{HCHO}+\mathrm{Mn}_{2} \mathrm{O}_{3}
$$

One of the disproportionational products, HCHO, was not detected in the mass spectrum. Then, it was further oxidized to $\mathrm{CO}_{2}$ and $\mathrm{H}_{2} \mathrm{O}$. The overall reactions with or without decomposi-

\section{【Gas chromatogram 】【Mass spectra 】}

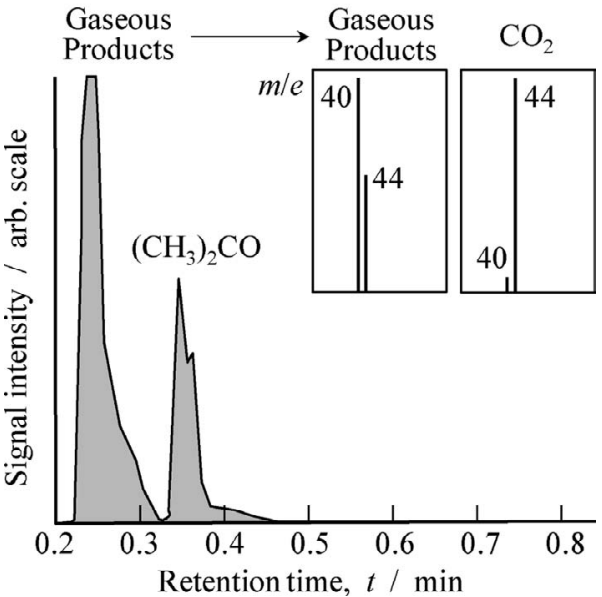

Fig. 6. Gas chromatogram and mass spectra of the gaseous product.

tion of $\mathrm{CH}_{3} \mathrm{CHO}$ were represented by Eqs. (2) and (3).

$$
\begin{aligned}
& \left(\mathrm{CH}_{3}\right)_{2} \mathrm{CO}+16 \mathrm{MnO}_{2} \rightarrow 3 \mathrm{CO}_{2}+3 \mathrm{H}_{2} \mathrm{O}+8 \mathrm{Mn}_{2} \mathrm{O}_{3} \\
& \left(\mathrm{CH}_{3}\right)_{2} \mathrm{CO}+6 \mathrm{MnO}_{2} \rightarrow \mathrm{CH}_{3} \mathrm{CHO}+\mathrm{CO}_{2}+\mathrm{H}_{2} \mathrm{O}+3 \mathrm{Mn}_{2} \mathrm{O}_{3}
\end{aligned}
$$

The relations between the bulk valence and the molar ratio $\left(\mathrm{CH}_{3}\right)_{2} \mathrm{CO} / \mathrm{MnO}_{2}$ according to Eqs. (2) and (3) are shown in Fig. 4. The observed relation agrees with Eq. (2) rather than Eq. (3). This is supported by the larger negative value of $\Delta G=-1320$ $\mathrm{kJ} \cdot \mathrm{mol}^{-1}$ for reaction (2) than $\Delta G=-453 \mathrm{~kJ} \cdot \mathrm{mol}^{-1}$ for reaction (3). The Acetone molecules were completely oxidized to $\mathrm{CO}_{2}$ and $\mathrm{H}_{2} \mathrm{O}$. Sixteen $\mathrm{Mn}^{4+}$ ions can be reduced to $\mathrm{Mn}^{3+}$ in compensation to the complete oxidation of one Acetone molecule. However, the formation of $\mathrm{CO}_{2}$ and $\mathrm{H}_{2} \mathrm{O}$ having higher adsorption ability decreased the efficiency by occupying the breakage sites of the double chains dominantly.

\subsection{Morphology and surface area of ground prod- ucts}

The formation of $\mathrm{H}_{2} \mathrm{O}$ suggested the increase in agglomeration ability of the ground products. The morphology of the ground products is shown in Fig. 7 with $S S A$. The ground product was agglomerated even for A0 without containing Acetone. The increase of the Acetone content resulted in the decrease of the size of agglomerates, while SSA decreased once for A1 and A2 and then increased for A $3<\mathrm{A} 4<\mathrm{A} 5$. The SSA increased by the pulverization of the agglomerates when $\mathrm{Mn}_{2} \mathrm{O}_{3}$ was formed. Figure 8 shows the integrated XRD peak intensity and the halfvalue width of the (222) reflection for $\mathrm{Mn}_{2} \mathrm{O}_{3}$ as the function of molar ratio $\left(\mathrm{CH}_{3}\right)_{2} \mathrm{CO} / \mathrm{MnO}_{2}$ after calcination. The integrated intensity for $\mathrm{A} 0, \mathrm{~A} 1$ and $\mathrm{A} 2$, where $\mathrm{MnO}_{2}$ was thermally reduced to $\mathrm{Mn}_{2} \mathrm{O}_{3}$, was almost the same at 500 and $800^{\circ} \mathrm{C}$. The half-value width for these ground products was low. Then, well-crystallized $\mathrm{Mn}_{2} \mathrm{O}_{3}$ was obtained by the thermal reduction. Contrary to this, the mechanochemically reduced $\mathrm{Mn}_{2} \mathrm{O}_{3}$ (A3-A5) indicated the poor crystallinity at $500^{\circ} \mathrm{C}$. The $S S A$ for the calcined products at $500^{\circ} \mathrm{C}$ was small for the thermally reduced $\mathrm{Mn}_{2} \mathrm{O}_{3}\left(15-13 \mathrm{~m}^{2} \cdot \mathrm{g}^{-1}\right.$ for $\mathrm{A} 0-\mathrm{A} 3)$, and increased for the mechanochemically reduced $\mathrm{Mn}_{2} \mathrm{O}_{3}$ (17, 18 1nd $20 \mathrm{~m}^{2} \cdot \mathrm{g}^{-1}$ for A3, A4 and A5, respectively). The peculiarity of mechanically enforced reduction products, fine particle size, agglomeration and the defected crystalline structure were preserved after calcination at $500^{\circ} \mathrm{C}$. 


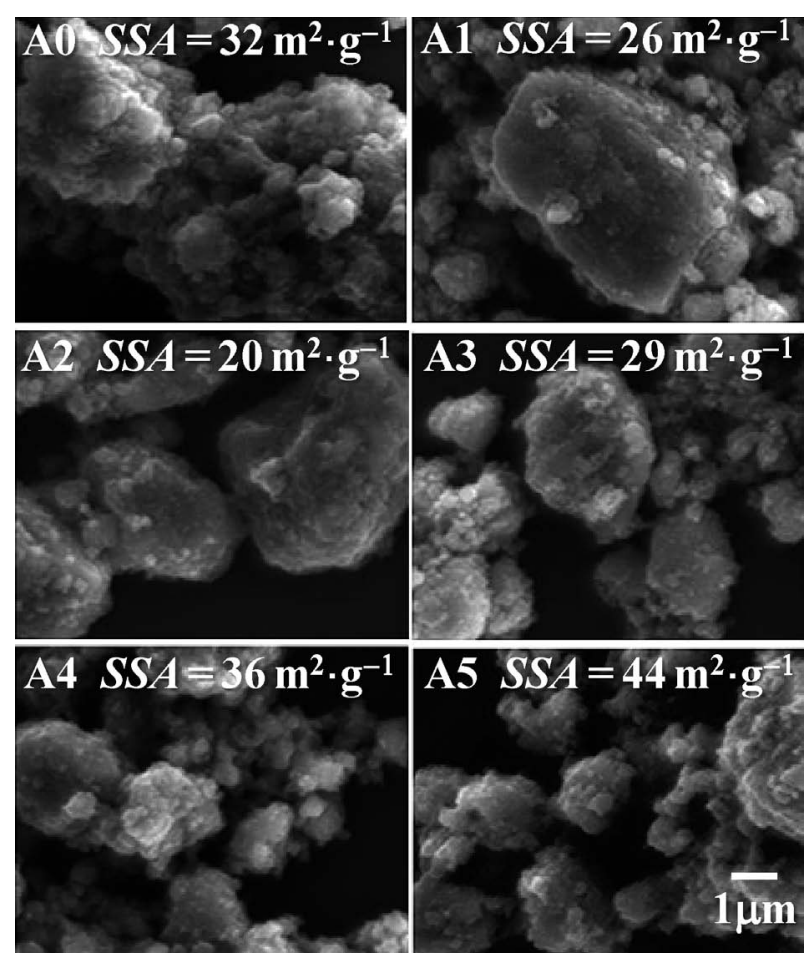

Fig. 7. Morphology and specific surface area (SSA) of the ground products.

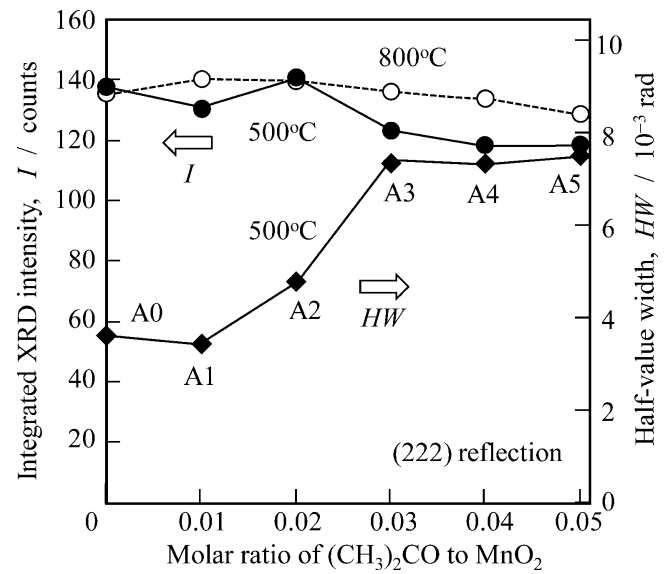

Fig. 8. Integrated XRD intensity $(I)$ and half-value width $(H W)$ of (222) reflection for $\mathrm{Mn}_{2} \mathrm{O}_{3}$ after calcination of the ground products in air.

3.4 Reduction ability of some ketones and alcohols

The reduction of $\mathrm{MnO}_{2}$ can be induced by the other organic vapors. Figure 9 shows the XRD profiles of the ground products in the atmosphere containing Acetone (A3), Methanol (M3), Ethanol (E3), 2-Butanone (B3), and 3-Pentanone (P3). The all ground products were the mixture of $\beta-\mathrm{MnO}_{2}$ and $\mathrm{Mn}_{2} \mathrm{O}_{3}$. The reduction to $\mathrm{Mn}_{2} \mathrm{O}_{3}$ was promoted for $\mathrm{A} 3, \mathrm{~B} 3$ and $\mathrm{E} 3$. The XPS spectra in Fig. 10 also indicated the higher peaks of $\mathrm{Mn}(\mathrm{III})$ for the 3 ground products. The surface and bulk valence of manganese ions were determined from the XPS and thermogravimetric data and listed in Table 1. On the assumption of the complete oxidation of the organic chemicals to $\mathrm{CO}_{2}$ and $\mathrm{H}_{2} \mathrm{O}$, one mole of Acetone, 2-Butanone, 3-Pentanone, Methanol and Ethanol can reduce 16, 22, 28, 6 and 12 moles of $\mathrm{Mn}^{4+}$ ions to $\mathrm{Mn}^{3+}$, respectively. The estimated bulk valence on this assumption was 3.44

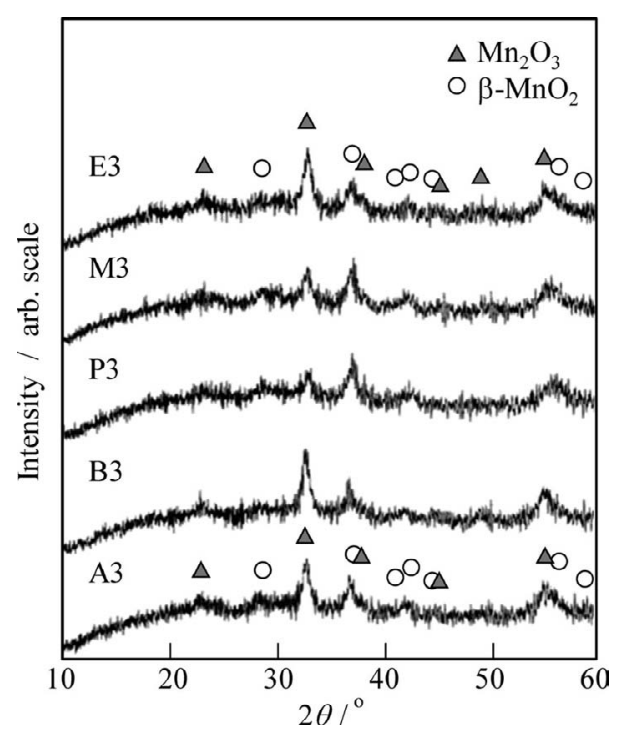

Fig. 9. Effect of some organic compounds on the reduction of manganese ions under grinding. A3: Acetone, B: 2-Butanone, P: 3-Pentanone, M: Methanol, and E: Ethanol.

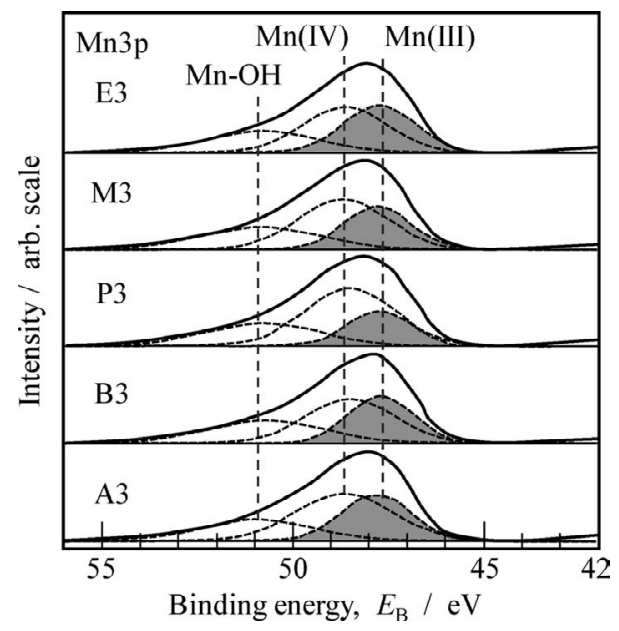

Fig. 10. XPS spectra (Mn3p) of the ground products in the atmosphere containing Acetone (A3), 2-Butanone (B), 3-Pentanone (P), Methanol (M) and Ethanol (E).

Table 1. Effect of Organic Compounds on Reduction of Manganese Ions

\begin{tabular}{cccccc}
\hline Sample & A3 & B3 & P3 & M3 & E3 \\
\hline Surface valence of Mn & 3.51 & 3.48 & 3.62 & 3.54 & 3.49 \\
Bulk valence of Mn & 3.59 & 3.54 & 3.74 & 3.70 & 3.67
\end{tabular}

(A3), 3.36 (B3), 3.32 (P3), 3.62 (M3), and 3.47 (E3). The efficiency for the observed degree of reduction was 0.727 (Acetone), 0.718 (2-Butanone), 0.382 (3-Propanone), 0.781 (Methanol) and 0.618 (Ethanol). The evidently low efficiency of 3-Propanone would be due to the low vapor pressure relating to the high boiling point. The saturated vapor pressure calculated by Antoine's equation was 81.8, 36.2, 15.8, 55.6 and $29.4 \mathrm{kPa}$ at $50^{\circ} \mathrm{C}$ for Acetone, 2Butanone, 3-Propanone, Methanol, and Ethanol, respectively. ${ }^{14)}$ The difficulty for the disproportionational reaction as the initiation process of the redox process would also relate to the low efficiency. 


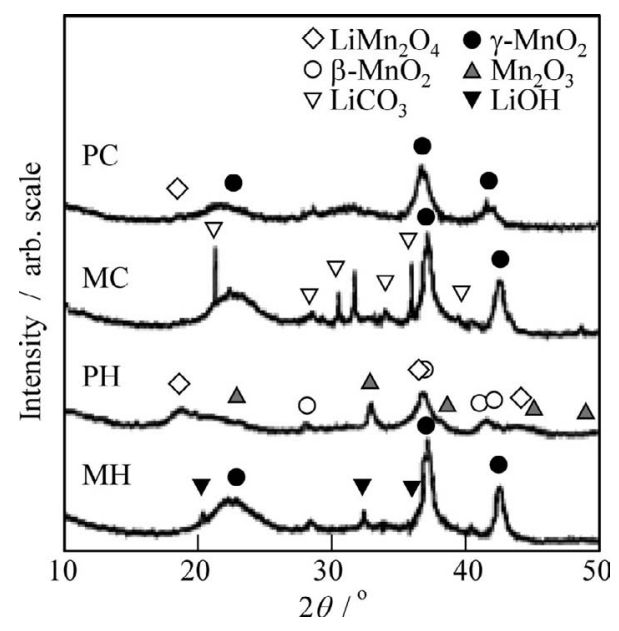

Fig. 11. XRD profiles of the ground products in $\mathrm{MnO}_{2}-\mathrm{Li}_{2} \mathrm{CO}_{3}$ system (PC/planetary mill, $\mathrm{MC} /$ mortar ground) and $\mathrm{MnO}_{2}-\mathrm{LiOH}$ system ( $\mathrm{PH} /$ planetary milled, $\mathrm{MH} /$ mortar ground).

\subsection{Application to the synthesis of $\mathrm{LiMn}_{2} \mathrm{O}_{4}$}

This redox process was applied to the synthesis of $\mathrm{LiMn}^{\mathrm{III}} \mathrm{Mn}^{\mathrm{IV}} \mathrm{O}_{4}$ as a cathode material for lithium batteries. The XRD profiles of the ground products in $\mathrm{LiCO}_{3}-\mathrm{MnO}_{2}(\mathrm{PC})$ and $\mathrm{LiOH}-\mathrm{MnO}_{2}(\mathrm{PH})$ systems are shown in Fig. 11 in comparison with those of mortar-ground ones ( $\mathrm{MC}$ and $\mathrm{MH})$. The Acetone content of $0.5 \mathrm{~cm}^{3}$ was a little higher than the requirement to reduce the half of $\mathrm{MnO}_{2}$ to $\mathrm{Mn}_{2} \mathrm{O}_{3}$ according to Eq. (2), because the reaction products $\mathrm{CO}_{2}$ from $\mathrm{Li}_{2} \mathrm{CO}_{3}(\mathrm{PC})$ and $\mathrm{H}_{2} \mathrm{O}$ from $\mathrm{LiOH}(\mathrm{PH})$ should disturb the reduction. The mortar ground mixtures showed the reflections for the starting $\mathrm{Li}_{2} \mathrm{CO}_{3}$ and $\mathrm{LiOH}$ as well as those for $\gamma-\mathrm{MnO}_{2}$. Contrary, for PC and $\mathrm{PH}$, reflections for $\mathrm{LiCO}_{3}$ and $\mathrm{LiOH}$ disappeared. The starting $\gamma-\mathrm{MnO}_{2}$ remained for PC but it was transformed to $\beta-\mathrm{MnO}_{2}$ and $\mathrm{Mn}_{2} \mathrm{O}_{3}$ for $\mathrm{PH}$. Additionally, the broad peak for $\mathrm{LiMn}_{2} \mathrm{O}_{4}$ appeared at $2 \theta=18.8^{\circ}$ for $\mathrm{PH}$. This strongly indicated the penetration of $\mathrm{Li}^{+}$ions into the lattice of $\gamma-\mathrm{MnO}_{2}$ to rearrange the lattice to $\mathrm{LiMn}_{2} \mathrm{O}_{4}$-like structure. The carbonate-derived PC had the deformed $\gamma-\mathrm{MnO}_{2}$ structure suggesting the dissolution of $\mathrm{Li}^{+}$ions. For both changes in the crystalline structure, parts of $\mathrm{Mn}^{4+}$ ions should be reduced to $\mathrm{Mn}^{3+}$.

$$
\begin{aligned}
& 1 / 2 \mathrm{Li}_{2} \mathrm{CO}_{3}+2 \mathrm{MnO}_{2} \rightarrow \mathrm{LiMn}_{2} \mathrm{O}_{4}+1 / 2 \mathrm{CO}_{2}+1 / 4 \mathrm{O}_{2} \\
& \mathrm{LiOH}+2 \mathrm{MnO}_{2} \rightarrow \mathrm{LiMn}_{2} \mathrm{O}_{4}+1 / 2 \mathrm{H}_{2} \mathrm{O}+1 / 4 \mathrm{O}_{2}
\end{aligned}
$$

These reactions were promoted by the reduction of $\mathrm{MnO}_{2}$ with the assistance of Acetone vapor removing oxygen.

The ground products $\mathrm{PC}$ and $\mathrm{PH}$ can be converted to the crystalline $\mathrm{LiMn}_{2} \mathrm{O}_{4}$ completely without forming by-products by the post heat-treatment at $700^{\circ} \mathrm{C}$ as shown in Fig. 12. The BETequivalent particle size of the calcined PC was 195, 293 and $459 \mathrm{~nm}$ at 600,700 , and $800^{\circ} \mathrm{C}$, respectively. The powders obtained from PH were smaller than PC; 153, 214 and $399 \mathrm{~nm}$ at the same temperatures. As described in a separate paper, ${ }^{12)}$ the fine powders prepared by the mechanochemical method indicate the excellent cycle performances for the rechargeability.

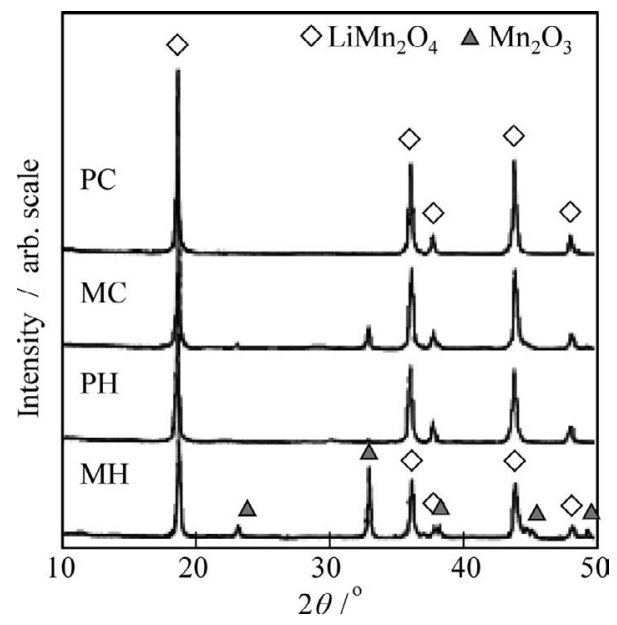

Fig. 12. XRD profiles of the calcined $\mathrm{PC}, \mathrm{MC}, \mathrm{PH}$ and $\mathrm{MH}$ at $700^{\circ} \mathrm{C}$ for $3 \mathrm{~h}$.

\section{Conclusion}

Mechanochemical reduction of $\mathrm{MnO}_{2}$ under grinding in the atmosphere containing organic vapors has been studied. Organic vapors such as Acetone, 2-Butanone, 3-Pentanone, Methanol and Ethanol has the activity to reduce $\mathrm{MnO}_{2}$ to $\mathrm{Mn}_{2} \mathrm{O}_{3}$. The reduction mechanism with the assistance of mechanical dissociation of edge-sharing $\mathrm{MnO}_{6}$-double chains of $\gamma-\mathrm{MnO}_{2}$ has been discussed. This redox process can be applied to the synthesis of $\mathrm{LiMn}_{2} \mathrm{O}_{4}$

\section{References}

1) O. Abe, J. Soc. Inorg. Mater. Japan, 15, 3-13 (2008).

2) F. Saito, Metals \& Technology, 69, 1082-1088 (1999).

3) M. Senna, Int'l. J. Inorg. Mater., 3 509-514 (2001).

4) Y. Suzuki and O. Abe, J. Soc. Powder Tech., Japan, 32, 639643 (1995)

5) O. Abe and Y. Suzuki, Mater. Sci. Forum, 225-227, 563-568 (1996).

6) O. Abe, K-. Q. Dinh and D. Itoh, Trans. Mater. Res. Soc. Jpn., 25, 131-134 (2000).

7) O. Abe and M. Narita, Solid State Ionics, 101-103, 103-109 (1997).

8) M. Koike and O. Abe, Solid State Ionics, 172, 217-220 (2004).

9) M. Koike, K. Tokumitsu and O. Abe, J. Soc. Powder Tech., Japan, 42, 419-425 (2005).

10) O. Abe, M. Koike and R. Umezawa, J. Soc. Powder Tech., Japan, 42, 199-205 (2005).

11) O. Abe, N. Mantoku, T. Yamada and S. Mitachi, Trans. Mater. Res. Soc. Jpn, 32, 123-126 (2007).

12) O. Abe, Y. Hosono, T. Sano and Y. Yoshizaki, Trans. Mater. Res. Soc. Jpn, 33, 941-944 (2008).

13) O. Abe, N. Mantoku, T. Yamada and S. Mitachi, Trans. Mater. Res. Soc. Jpn, 33, 945-948 (2008).

14) Chem. Soc. Jpn. (Ed.), "Handbook for Chemistry (KagakuBinran), Ver. 2, Kiso-hen 2,” Maruzen, Tokyo (1975) pp.711730 . 